\title{
New Approach in the Fault Tolerant Control of Three-Phase Inverter Fed Induction Motor
}

\author{
Zouhir Boumous \\ Laboratory of Electrical Engineering and Renewable Energies \\ Mohamed Cherif Messaidia University \\ Souk Ahras, Algeria \\ zsid3@yahoo.fr
}

\author{
Samira Boumous \\ Laboratory of Electrical Engineering and Renewable Energies \\ Mohamed Cherif Messaidia University \\ Souk Ahras, Algeria \\ boumous@yahoo.fr
}

\begin{abstract}
This article provides an improved fault-tolerant control scheme for inverter-powered induction motors. The proposed strategy addresses the cancellation of power switch failures (IGBTs) regardless of their location in a reconfigurable induction motor control. The proposed fault-tolerant topology requires only minimal hardware modifications of the conventional sixswitch three-phase drive, mitigating IGBT failures through reconfiguration based on the substitution of an entire inverter arm. The detection mechanism is based on the tridimensional method from which a database will be used for the learning of the neural network. In this method, the current from the stator is used as input to the system, so access to the induction motor is not necessary.
\end{abstract}

Keywords-inverter; induction motor; artificial neural networks; diagnosis; fault tolerant control

\section{INTRODUCTION}

It is estimated that around $38 \%$ of faults in variable speed drives in the industry are caused by power supply device failures [1]. Most of the inverters use isolated IGBTs as power devices. This percentage would be higher if the control circuit failures were taken into account. They consist of faults such as intermittent inverter misfiring due to faults in the control circuit elements or electromagnetic interference which results in gate drive opening faults, and therefore leads to an open IGBT circuit. Although IGBTs are rugged, they experience failures due to the excessive electrical and thermal stresses that are felt in harsh environments. IGBT failures can be broadly classified as open circuit faults, short circuit faults, and intermittent gate trip faults [2]. Variable speed drives, and the inverter in particular, are occupying more and more space. This rapidly increases the concern for fault tolerance due to availability problems $[1,3]$. When inverter faults appear, the conventional topology of the EV powertrain cannot perform its function of traction of the vehicle, therefore the need to develop fault tolerant systems emerges.

The two most common types of power converter faults that have been widely investigated are the transistor gate driver open fault or the IGBT open circuit switch and the short circuit switch. These two faults can lead to catastrophic drive failures or significantly degraded performance [4]. It is therefore crucial to be able to detect and diagnose these two faults in order to take the appropriate corrective measures to mitigate their effects [5-8]. A priori knowledge of faults is assumed in this paper and the emphasis will be on corrective actions in the event of a fault. Once the fault is detected and located, corrective action must be taken to mitigate the effects of the fault [9-11]. Many inverter architectures based on some hardware redundancy have been suggested to add reconfigurability to the system $[12,13]$. Several studies have invested in this subject. Authors in [14] have proposed a detection mechanism based on a new wavelet transformation technique. Authors in [15] proposed a non-intrusive faultdiagnosis method for open-circuit faults in inverter semiconductor power switches, whereas authors in [16] proposed another model: when an open-circuit fault occurs regardless of the position of the rectifier leg, an indication will be generated in the absence of any additional sensors to accurately identify the defective leg. Authors in [17] described a method based on vector space decomposition and double three-phase space vector modulation. Diagnostic and tolerant control methods have been developed comprehensively for three types of faults, open-switch faults, open-phase faults and short-switch faults in a three-level type T inverter supplied by a double three-phase PMSM drives. The strategy proposed in [18] belongs to the bridge-arm level, with a redundant bridge arm in parallel. When the bridge arm is an open or short circuit during operation, the redundant bridge arm will replace it and keep the system working as normal. Authors in [19] proposed a fault-tolerant scheme based on changing the inverter topology from six to four switches to ensure proper operation. In the event of a fault, a connection to the midpoint of the circuit based on an external switch and a disconnection of the phase terminal of the motor of the defective inverter arm is obtained.

The proposed diagnosis method is based on the neural network analysis of the mean values of the stator currents of the MAS in a tridimensional space, by calculating all the angles that separate them, and subsequently the fault tolerant command reconfigures the system and its operation returns to normal.

\section{CIRCUIT TOPOLOGY OF TRACTION INVERTER}

The circuit topology of the two-level three-phase inverter is shown in Figure 1. $T_{1}, T_{2} \ldots T_{6}$ are IGBTs and $D_{1}, D_{2} \ldots D_{6}$ are anti-parallel diodes. An induction motor is located at the load side. 


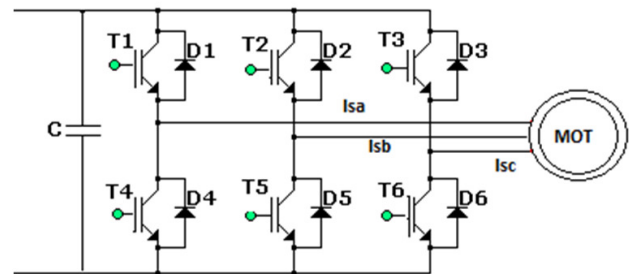

Fig. 1. Circuit yopology of a two-level three-phase inverter.

\section{IGBT OPEN-CIRCUIT FAULT ANALYSIS}

In order to show the robustness of the proposed approach, the open circuit faults in the IGBTs given in Figure 2 are considered. The previously proposed approaches treat cases (a) and (b) but remain unable to deal with the case (c) because they are based on the substitution of the whole arm. In case (c) of Figure 2, the switches are placed in two different arms [20], thus, they are obliged to double the emergency arms. The proposed approach consists in replacing the faulty switch by an adequate reconfiguration according to the position of the switch shown in Figure 2. So, a second redundant switch is always available and ready to emerge to remedy other faults in other locations.

(a)

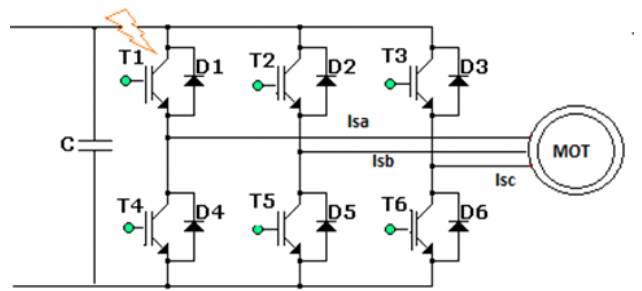

(b)

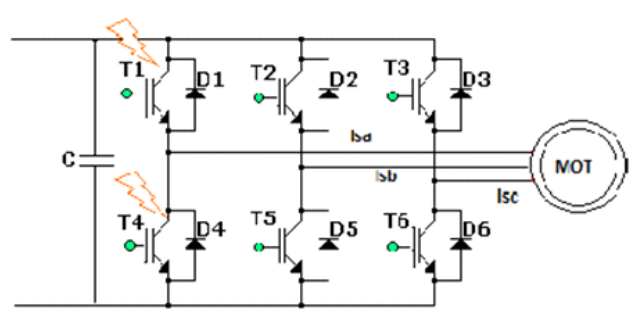

(c)

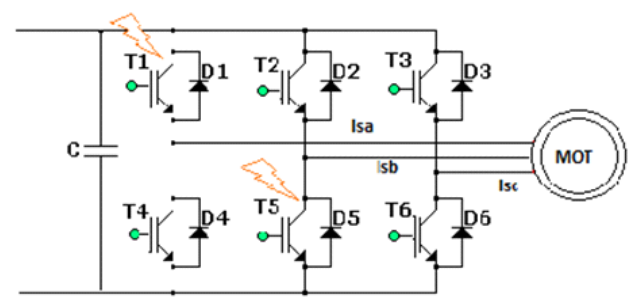

Fig. 2. Open circuit fault positions: (a) one IGBT, (b) two IGBTs in the same arm, (c) two IGBTs in two different arms.

\section{A. Double-switch Faults in the Same Bridge Arm (T1-T4)}

The two switches are located on the first arm of the inverter so the current Isa is seriously affected in relation with the other two currents $I s b$ and $I s c$. When open-circuit faults occur in the double switches in the same bridge arm, taking open-circuit faults in T1 and T4 as an example, they cannot be turned on normally. Neither positive nor negative half-cycle currents can complete the continuation, therefore phase $\mathrm{A}$ is equivalent to an open circuit. The other two-phase switches are working normally. The current of phase A is zero and the current of the other two phases is distorted. The current waveform is shown in Figure 3.
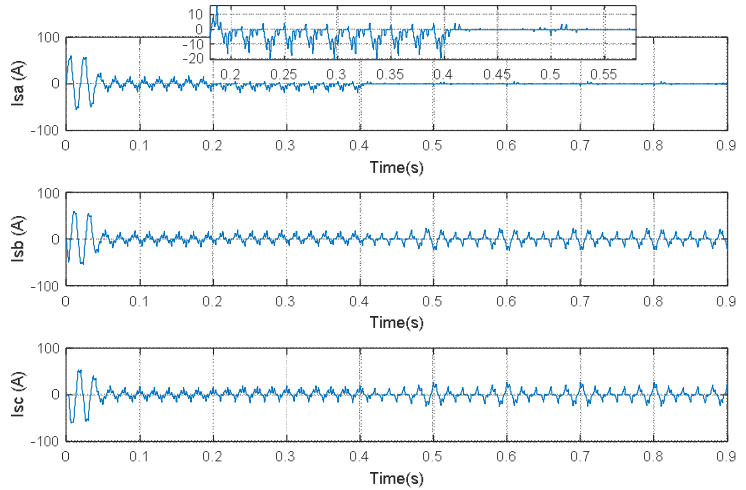

Fig. 3. Current waveforms of two switch faults in the same bridge arm.

After opening the switches T1 at $t=0.2 \mathrm{~s}$ we can clearly see in Figure 3 that the positive half-wave of Isa becomes zero and a slight modification appears on the Isb and Isc currents. At $t=0.4 \mathrm{~s}, \mathrm{~T} 4$ joins $\mathrm{T} 1$ and becomes open and the current $I s a$ becomes zero. Opening an arm is similar to opening a phase. The amplitudes of the other two currents are 15 to $20 \mathrm{~A}$.

B. Double-switch Faults in Different Bridge Arms (T1-T5)

When double switches in different bridge arms are in opencircuit fault status, the situation can be further classified into two cases. The first is the one where two IGBTs at the same half-bridge position in the two bridge arms (such as T1 and T5) are in open circuit fault status. The second is where two IGBTs at different half-bridge positions in the two bridge arms are in open-circuit fault status. Faults in T1 and T5 are taken here as an example of double switches in different bridge arms in open-circuit fault status. The current waveform is shown in Figure 4.
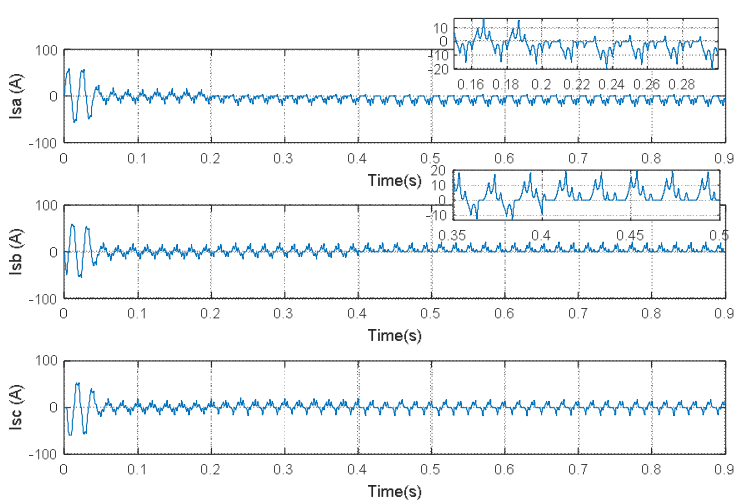

Fig. 4. Current waveforms of two switch faults in different bridge arms at two different times. 

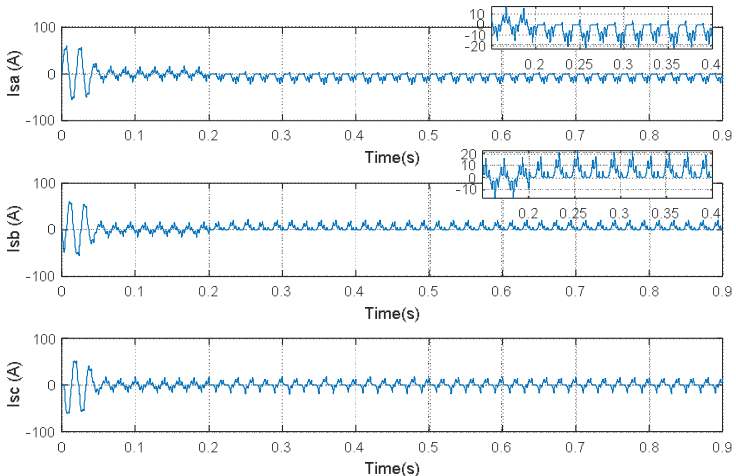

Fig. 5. Current waveforms of two switch faults in different bridge arms at the same time.

By introducing the open-circuit fault, the waveforms of the three-phase currents are distorted and become asymmetric, so the output electromagnetic torque of the traction motor is reduced and oscillates severely, which is harmful for the system's security and stability. The increase in the amplitudes of the currents leads to the motor heating up, especially when the load torque becomes greater, so the winding risks being damaged. Immediate intervention, i.e. replacing the faulty switch in a very short time becomes essential for the continuity of service, otherwise the risk of an abrupt shutdown is very high. The developed intervention strategy is summarized in Figure 6.

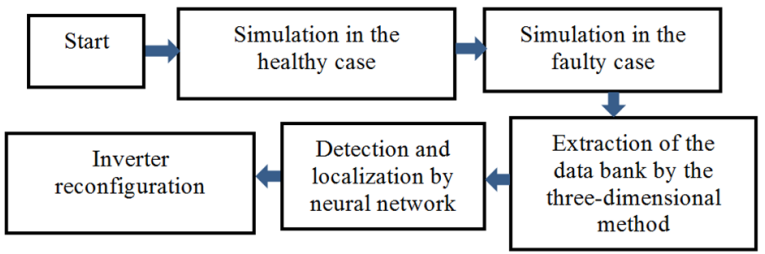

Fig. 6. Flowchart of the control and fault detection strategy.

\section{TRIDIMENSIONAL METHOD FOR FAULT DIAGNOSIS}

From the synthesis of the results obtained previously, it is concluded that the three-phase current will be distorted in the event of an open circuit fault, which can be considered as a fault signature, whether the fault phase current is zero or not. In order to accurately acquire fault features and determine the fault location, we extract characteristics from the tridimensional analysis of the three-stator current. The feature extraction is the most important step in the proposed defect detection and classification process. Better features will lead to better performance and to a more reliable system. In this research, the feature extraction technique transforms the threephase output into instantaneous waveforms constructed from the average values of stator currents. Under normal conditions, these instantaneous values create a circle-like shape with some fluctuations in a tridimensional presentation space, as shown in Figure 7. Each system failure causes disturbances in the threephase current which changes its shape in a unique way.

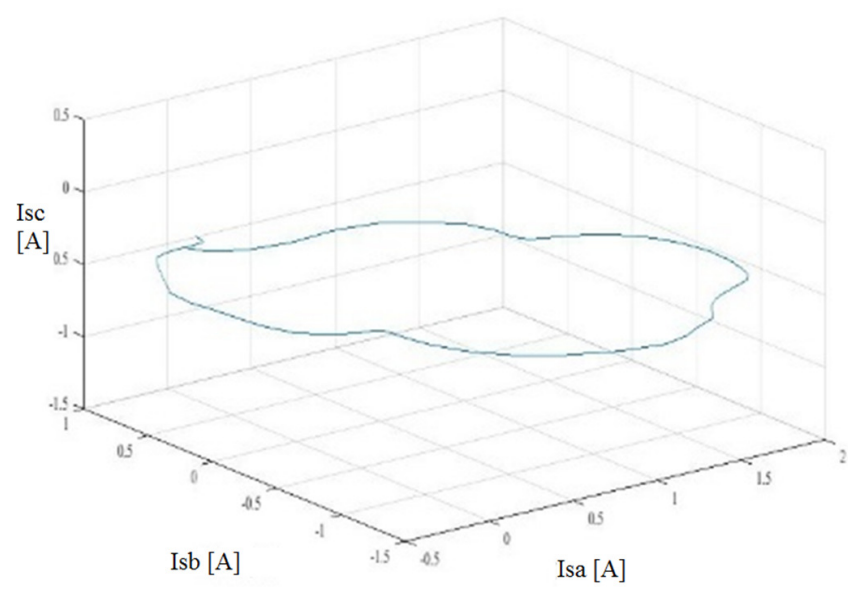

Fig. 7. The shape of the $\mathrm{Is}_{\text {mean }}$ stator currents in a healthy state.

The defect reaches the two sizes:

- The radius of the tridimensional circle:

$$
R^{2}=I_{a(\text { mean })}^{2}+I_{b(\text { mean })}^{2}+I_{c(\text { mean })}^{2}
$$

This property can be restricted to the analysis of the mean values of the currents:

$$
I_{a(\text { mean })}=\sum I_{a} / N
$$

- The angles of the mean values:

The average values of the three stator currents are placed on the axes of an orthogonal three-dimensional coordinate system. Angles 1-6 are based on these average values, the presence of a fault affects the average value of the currents which directly influences these angles as shown in Figure 8.

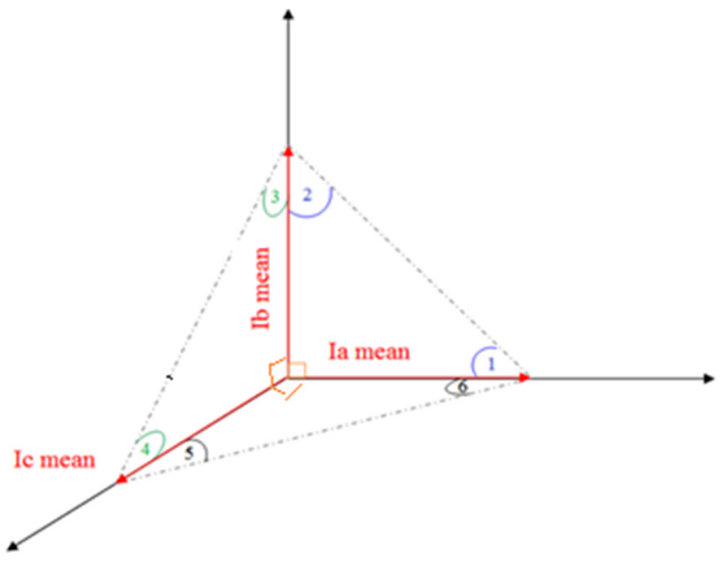

Fig. 8. Representation of the 6 characteristic angles.

The next characteristic to extract is the angle of each mean with respect to its axis. The angle at the mean value gives us the exact location of this point in the tridimensional space of Figure 8 . These angles are explicitly calculated as :

$$
\begin{aligned}
& \text { Angle (1) }: \operatorname{Atan}(B A)=\tan ^{-1}\left(\frac{I_{\text {bmean }}}{I_{\text {amean }}}\right) \\
& \text { Angle (2) }: \operatorname{Atan}(A B)=\tan ^{-1}\left(\frac{I_{\text {amean }}}{I_{\text {bmean }}}\right)
\end{aligned}
$$




$$
\begin{aligned}
& \text { Angle (3) }: A \tan (C B)=\tan ^{-1}\left(\frac{I_{\text {cmean }}}{I_{\text {bmean }}}\right) \\
& \text { Angle (4) }: \operatorname{Atan}(B C)=\tan ^{-1}\left(\frac{I_{\text {bmean }}}{I_{\text {cmean }}}\right) \\
& \text { Angle (5) }: \operatorname{Atan}(A C)=\tan ^{-1}\left(\frac{I_{\text {mean }}}{I_{\text {cmean }}}\right) \\
& \text { Angle (6) }: \operatorname{Atan}(C A)=\tan ^{-1}\left(\frac{I_{\text {cmean }}}{I_{\text {amean }}}\right)
\end{aligned}
$$

\section{NEURAL NETWORK LEARNING PROCEDURE}

This technique has very interesting characteristics such as learning and self-organization. Neural networks can be thought of as black boxes [21-22]. The calculation of the mean values of the currents and the angles which separate them in the tridimensional space leads to the results presented in tabulated form in Figure 9.

\begin{tabular}{|l|l|l|l|l|l|l|l|l|l|}
\hline Faults & Angle 1 & Angle 2 & Angle 3 & Angle 4 & Angle 5 & Angle 6 & $\begin{array}{l}\text { Ia } \\
\text { mean }\end{array}$ & $\begin{array}{l}\text { Ib } \\
\text { mean }\end{array}$ & $\begin{array}{l}\text { Ic } \\
\text { mean }\end{array}$ \\
\hline T1 & -0.45 & -0.48 & -1.09 & 0.75 & -1.12 & 0.82 & -4.4 & 2.12 & 2.28 \\
T1-T4 & 1.45 & -1.47 & -0.14 & 0.73 & 0.12 & -0.84 & -0.06 & -0.49 & 0.55 \\
T1-T5 & -0.62 & -0.28 & -1.29 & 1.18 & -0.95 & 0.39 & -5.13 & 3.63 & 1.5 \\
\hline & $\cdot$ & $\cdot$ & $\cdot$ & $\vdots$ & $\vdots$ & $\vdots$ & $\vdots$ & $\vdots$ & $\vdots$ \\
\hline
\end{tabular}

Fig. 9. Extract characteristics table.

The table in Figure 9 is used to train the neural network which contains:

- An input layer of 9 elements which are the three average values of the currents and the 6 characteristic angles.

- A hidden layer of 24 neurons.

- A 6 element output layer that indicates the damaged switch (Figure 10).

The output layer presents faulty switches by thresholds, (1 indicates that the switch is damaged, 0 for healthy switches).

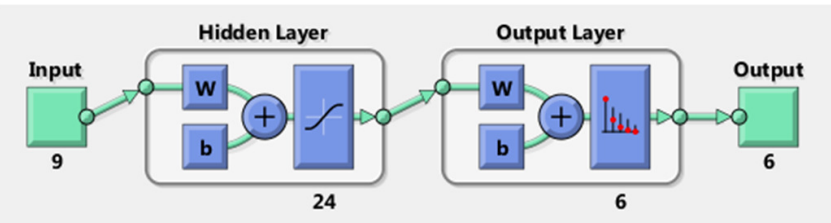

Fig. 10. The proposed artificial neural network architecture.

\section{CONTROL STRATEGY}

After the detection of a fault by the monitoring system, the FTC command intervenes to replace the faulty switch with a backup one, along with its appropriate command, to restore the correct functioning of the system. The simulation blocks for the monitoring of the system are shown in Figures 11-12. From the stator currents, angles and average values are calculated (Figure 12). These parameters train the artificial neural network which has the role of detecting the faulty switch and locating its location in a precise way, i.e. the neural network must provide three signals (Figure 13). Two signals control two multi-port switches which control the signals of the six switches (Figure 14(a)), one for the upper part of the inverter half bridge and the other for the lower part. In the faulty case these signals give the number of the switch in question, whereas in the healthy case these signals are equal to 0 .

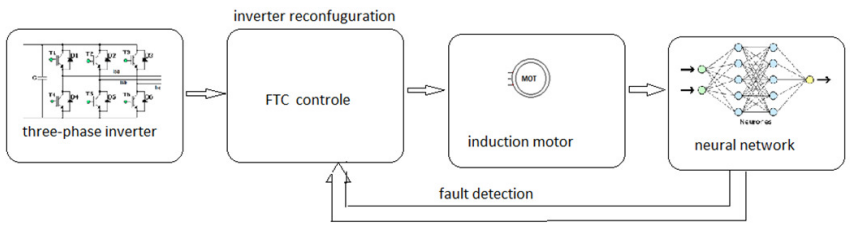

Fig. 11. Global simulation model.

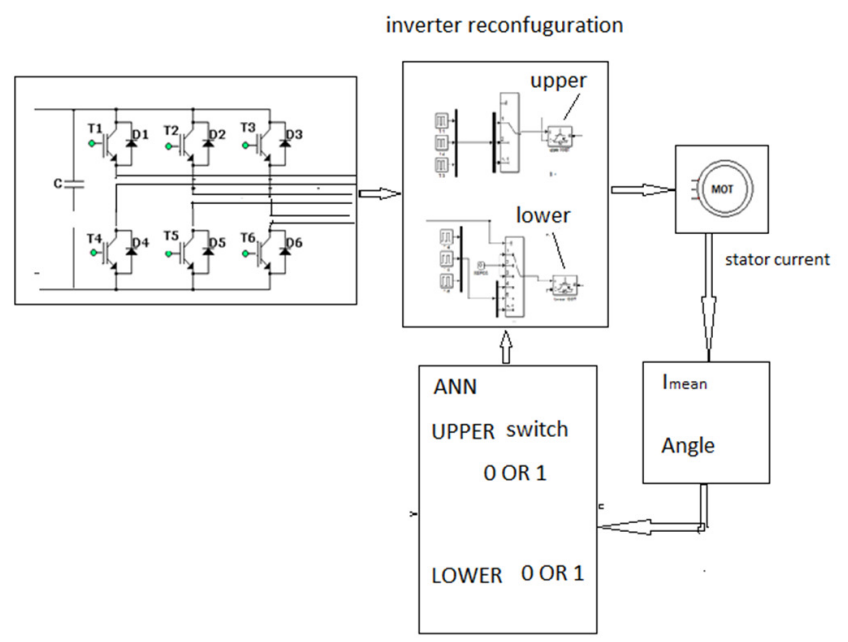

Fig. 12. The configuration system by FTC.

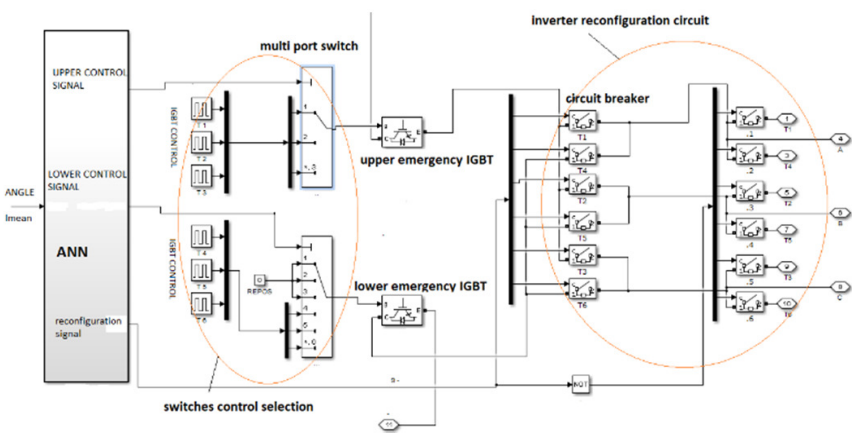

Fig. 13. Switches control selection and inverter reconfiguration strategy.

Figure 14(a) shows the output signals of the neural network when T3 is in open circuit. We see that the signal corresponds to the upper part is equal to 3 . This indicates that the third switch of the upper part of the half bridge of the inverter is faulty and the signal from the lower part is equal to 0 , i.e. that all the switches on the lower part of the inverter half-bridge are healthy. The third signal (Figure 14(b)) controls a reconfiguration card based on breaker circuits which has the role of isolating the faulty switch and putting an emergency switch in its exact place. 
(a)
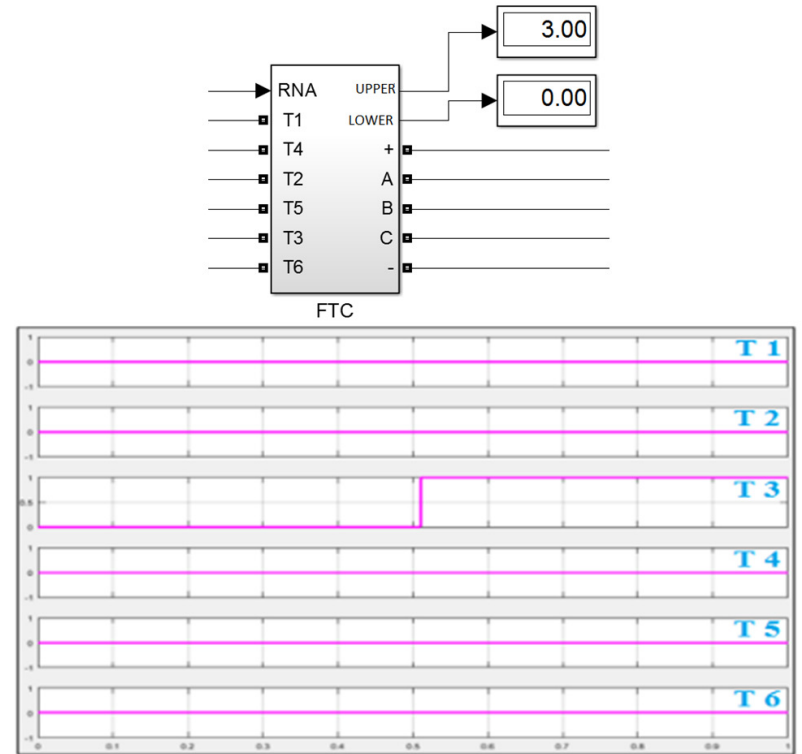

Fig. 14. Detecting single switch in the upper half bridge inverter $\mathrm{T} 3$ by the ANN: (a) detection and localization of a single switch fault by the ANN, (b) signals obtained by ANN for T3 open circuit.

\section{RECONFIGURATION SYSTEM TEST AND SIMULATION RESULTS}

For this type of fault, the appearance of a single fault and of two faults at the same time (multiple) are examined.

\section{1) Single Switch Fault}

The opening of the switch $\mathrm{T} 1$ at the instant $t=0.3 \mathrm{~s}$ is shown in Figure 15.
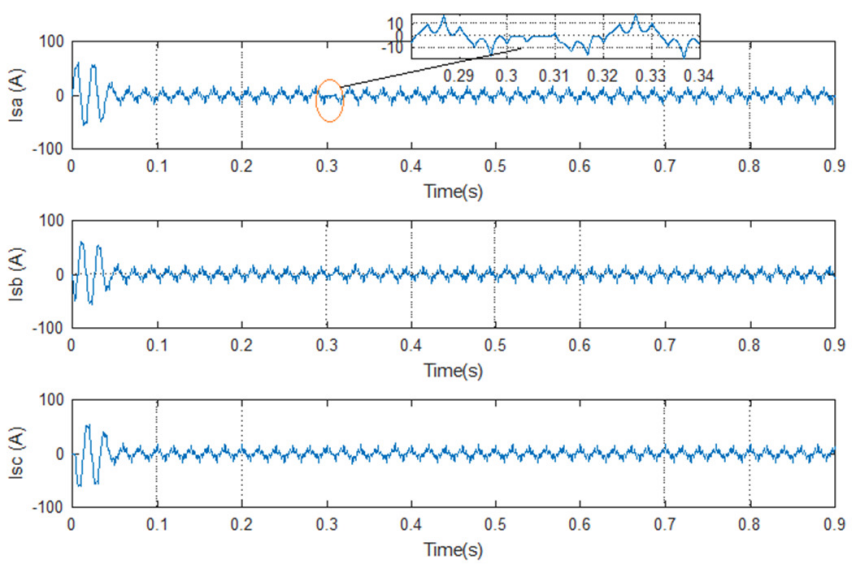

Fig. 15. FTC for a single switch open circuit.

\section{2) Failure of Two Switches of the Same Arm}

The switch T1 breaks down at the instant $t=0.3 \mathrm{~s}$ and the switch T4 at the instant $t=0.55 \mathrm{~s}$ as shown in Figure 16 .

\section{3) Faults of Two Switches in Two Different Arms}

We examine the opening of the second arm T1 at $t=0.3 \mathrm{~s}$ and $\mathrm{T} 5$ at $t=0.55 \mathrm{~s}$ as shown in Figure 17.
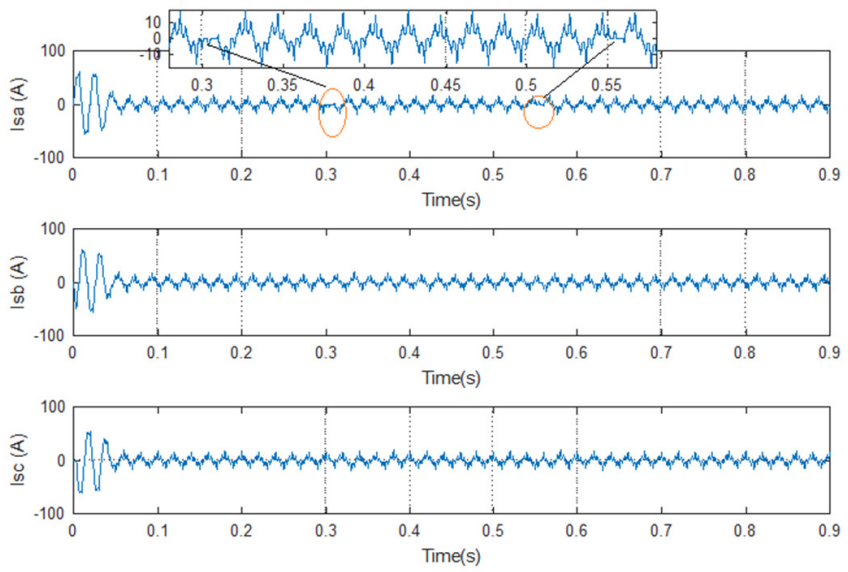

Fig. 16. FTC for an open circuit of two switches in the same inverter arm.
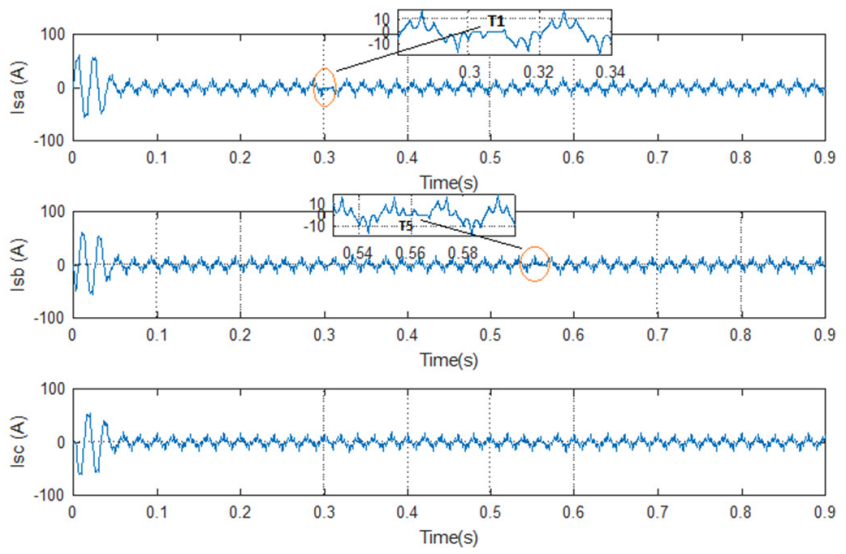

Fig. 17. FTC for an open circuit of two switches in different inverter arms.

The fault appears at $t=0.3 \mathrm{~s}$ : the switch T1 remains open due to a fault (Figure 17). This clearly results in the disappearance of the positive half-wave of the current Isa. Ensured by T1, the system employ detects, locates, and replaces it by a redundant switch by reconfiguring the inverter connections in order to isolate the faulty IGBT and connect the reserve one in its place to ensure the continuity of service. The procedure lasts for a very short time of around $0.01 \mathrm{~s}$. Its robustness and its ability to deal with multiple faults are proved in situations such as the one described in Figure 16, where two switches of the same arm T1 and T4 break down. The intervention of the system is very fast and the current becomes sinusoidal with two alternates, symmetrical and equal. The same observations remain valid for the third studied case, although the two switches are not on the same arm T1 in the first arm while T5 is located on the second arm. Figure 17 shows that the two currents $I s a$ and $I s b$ are clearly affected, the first by the absence of a positive half-wave and the second by the absence of the negative half-wave. The intervention of the monitoring system to be used again proves a very satisfactory efficiency by eliminating the faults in a very short time of the order of $0.01 \mathrm{~s}$.

At this stage, we can deduce that the strategy employed in the present work is very reliable, fast and acts in all possible 
fault scenarios. But the strong point that distinguishes this approach from other works is its simplicity. A simple mathematical calculation is enough to accomplish the task. In addition, the reconfiguration card does not require much to compose which facilitates the practical realization of this strategy with a reasonable price. Most other works are based on complicated techniques such as the fast Fourier transform [23], the wavelet transform [24], Clarke vectors [25], etc.

\section{CONCLUSION}

In an effort to ensure the continuity of service in induction motor drives, this article has summarized all the possible open circuit fault conditions in a three-arm inverter with two back-up switches. The fault detection method used is based on a neural network which learned from a database extracted from the tridimensional analysis of the stator currents. Finally, a fault tolerance strategy has been put in place which takes care of the reconfiguration of the inverter deemed necessary by the neural network by replacing the faulty switch with one of the two emergency available switches. The FTC module which isolates the faulty switch is put in its place in very satisfactory time. The simulation results proved the efficiency and robustness of the proposed strategy considering fault diversity and very short intervention times.

\section{REFERENCES}

[1] R. Maamouri, M. Trabelsi, M. Boussak, and F. M'Sahli, "Fault Diagnosis and Fault Tolerant Control of a Three-Phase VSI Supplying Sensorless Speed Controlled Induction Motor Drive," Electric Power Components and Systems, vol. 46, no. 19-20, pp. 2159-2173, Dec. 2018, https://doi.org/10.1080/15325008.2018.1534899.

[2] R. P. Vieira, C. C. Gastaldini, R. Z. Azzolin, and H. A. Gründling, "Sensorless Sliding-Mode Rotor Speed Observer of Induction Machines Based on Magnetizing Current Estimation," IEEE Transactions on Industrial Electronics, vol. 61, no. 9, pp. 4573-4582, Sep. 2014, https://doi.org/10.1109/TIE.2013.2290759.

[3] M. Bermudez, I. Gonzalez-Prieto, F. Barrero, H. Guzman, M. J. Duran, and X. Kestelyn, "Open-Phase Fault-Tolerant Direct Torque Control Technique for Five-Phase Induction Motor Drives," IEEE Transactions on Industrial Electronics, vol. 64, no. 2, pp. 902-911, Feb. 2017, https://doi.org/10.1109/TIE.2016.2610941.

[4] H. Liu, K. Ma, C. Wang, and F. Blaabjerg, "Fault Diagnosis and Faulttolerant Control of Modular Multi-level Converter High-voltage DC System: A Review," Electric Power Components and Systems, vol. 44, no. 16 , pp. 1759-1785, Oct. 2016, https://doi.org/10.1080/ 15325008.2016.1198439.

[5] H. Liu, P. C. Loh, and F. Blaabjerg, "Review of fault diagnosis and fault-tolerant control for modular multilevel converter of HVDC," in IECON 2013 - 39th Annual Conference of the IEEE Industrial Electronics Society, Vienna, Austria, Nov. 2013, pp. 1242-1247, https://doi.org/10.1109/IECON.2013.6699310.

[6] A. S. Abdel-Khalik, M. A. Elgenedy, S. Ahmed, and A. M. Massoud, "An Improved Fault-Tolerant Five-Phase Induction Machine Using a Combined Star/Pentagon Single Layer Stator Winding Connection," IEEE Transactions on Industrial Electronics, vol. 63, no. 1, pp. 618628, Jan. 2016, https://doi.org/10.1109/TIE.2015.2426672.

[7] M. J. Duran and F. Barrero, "Recent Advances in the Design, Modeling, and Control of Multiphase Machines-Part II," IEEE Transactions on Industrial Electronics, vol. 63, no. 1, pp. 459-468, Jan. 2016, https://doi.org/10.1109/TIE.2015.2448211.

[8] U. Choi, F. Blaabjerg, and K. Lee, "Study and Handling Methods of Power IGBT Module Failures in Power Electronic Converter Systems," IEEE Transactions on Power Electronics, vol. 30, no. 5, pp. 2517-2533, May 2015, https://doi.org/10.1109/TPEL.2014.2373390.

[9] J.-H. Song and K.-H. Kim, "Reliable Open-switch Fault Localization Scheme in Multiple Switches for Inverter-fed Permanent Magnet
Synchronous Machine Drives," Electric Power Components and Systems, vol. 45, no. 18, pp. 1973-1984, Nov. 2017, https://doi.org/ $10.1080 / 15325008.2017 .1401685$.

[10] W. Sun, J. Gao, X. Liu, Y. Yu, G. Wang, and D. Xu, "Inverter Nonlinear Error Compensation Using Feedback Gains and Self-Tuning Estimated Current Error in Adaptive Full-Order Observer," IEEE Transactions on Industry Applications, vol. 52, no. 1, pp. 472-482, Jan. 2016, https://doi.org/10.1109/TIA.2015.2480852.

[11] S. Chafei, F. Zidani, R. Nait-Said, and M. s Boucherit, "Fault Detection and Diagnosis on a PWM Inverter by Different Techniques," Journal of Electrical Systems, vol. 4, no. 2, pp. 1-12, Jun. 2008.

[12] B. D. E. Cherif, A. Bendiabdellah, M. Bendjebbar, and L. Souad, “A Comparative Study on Some Fault Diagnosis Techniques in Three-Phase Inverter Fed Induction Motors," Fault Detection and Diagnosis, Nov. 2018, https://doi.org/10.5772/intechopen.79960.

[13] Y. B. S. S. Gupta and S. S. Rao, "A modified inverter topology for faulttolerant direct torque control induction motor drive," International Journal of Electronics, Apr. 2020, https://doi.org/10.1080/ 00207217.2020 .1756445 .

[14] M. S. Khanniche and M. R. Mamat-ibrahim, "Fault Detection and Diagnosis of 3-Phase Inverter System," in Rev. Energ. Ren.: Power Engineering, 2001, pp. 69-75.

[15] S. Cheng et al., "An open-circuit fault-diagnosis method for inverters based on phase current," Transportation Safety and Environment, vol. 2, no. 2, pp. 148-160, Jun. 2020, https://doi.org/10.1093/tse/tdaa008.

[16] C. Shu, L. Wei, D. Rong-Jun, and C. Te-Fang, "Fault Diagnosis and Fault-Tolerant Control Scheme for Open-Circuit Faults in Three-Stepped Bridge Converters," IEEE Transactions on Power Electronics, vol. 32, no. 3, pp. 2203-2214, Mar. 2017, https://doi.org/10.1109/ TPEL.2016.2558491.

[17] X. Wang, Z. Wang, Z. Xu, J. He, and W. Zhao, "Diagnosis and Tolerance of Common Electrical Faults in T-Type Three-Level Inverters Fed Dual Three-Phase PMSM Drives," IEEE Transactions on Power Electronics, vol. 35, no. 2, pp. 1753-1769, Feb. 2020, https://doi.org/ 10.1109/TPEL.2019.2920400.

[18] J. Andreu, I. Kortabarria, E. Ibarra, I. M. de Alegría, and E. Robles, “A new hardware solution for a fault tolerant matrix converter," in 2009 35th Annual Conference of IEEE Industrial Electronics, Nov. 2009, pp. 4469-4474, https://doi.org/10.1109/IECON.2009.5414858.

[19] E. Z. M. Salem, A. H. Z, A.-G. S. F, and M. M. Elkholy, "Open gate fault diagnosis and tolerant for voltage source inverter fed speed sensorless induction motor drive," International Journal of Electronics, vol. 107, no. 11 , pp. 1754-1772, Nov. 2020, https://doi.org/10.1080/ 00207217.2020 .1756434$.

[20] Xu, S., Wang, C., Lin, F. et al. Fault-Tolerant Control of ANPC ThreeLevel Inverter Based on Order-Reduction Optimal Control Strategy under Multi-Device Open-Circuit Fault. Sci Rep 7, 14447, 2017.

[21] K. S. Belkhir, "Intelligent Maximum Power Tracking Control For a Wind Energy System Based on Magnetic Gear Generator," Engineering, Technology \& Applied Science Research, vol. 9, no. 4, pp. 4329-4333, Aug. 2019, https://doi.org/10.48084/etasr.2851.

[22] J. Chakravorty, S. Shah, and H. N. Nagraja, "ANN and ANFIS for Short Term Load Forecasting," Engineering, Technology \& Applied Science Research, vol. 8, no. 2, pp. 2818-2820, Apr. 2018, https://doi.org/10.48084/etasr.1968.

[23] B. Cai, Y. Zhao, H. Liu, and M. Xie, "A Data-Driven Fault Diagnosis Methodology in Three-Phase Inverters for PMSM Drive Systems," IEEE Transactions on Power Electronics, vol. 32, no. 7, pp. 5590-5600, Jul. 2017, https://doi.org/10.1109/TPEL.2016.2608842.

[24] S. Qiang and Y. Li, "Motor Inverter Fault Diagnosis Using Wavelets Neural Networks," in 2013 IEEE International Conference on Systems, Man, and Cybernetics, Manchester, UK, Oct. 2013, pp. 3168-3173, https://doi.org/10.1109/SMC.2013.540.

[25] A. Rohan and S. H. Kim, "Fault Detection and Diagnosis System for a Three-Phase Inverter Using a DWT-Based Artificial Neural Network," International Journal of Fuzzy Logic and Intelligent Systems, vol. 16, no. 4, pp. 238-245, Dec. 2016, https://doi.org/10.5391/IJFIS.2016. 16.4.238. 